\title{
BEDFORD/ST. MARTIN'S
}

\section{Available for fall}

Help students

discover why and how

literature matters



bedfordstmartins.com/ makinglitmatter/catalog

Talk about literature...



bedfordstmartins.com/ charters/catalog
Jump right in... the literature's fine

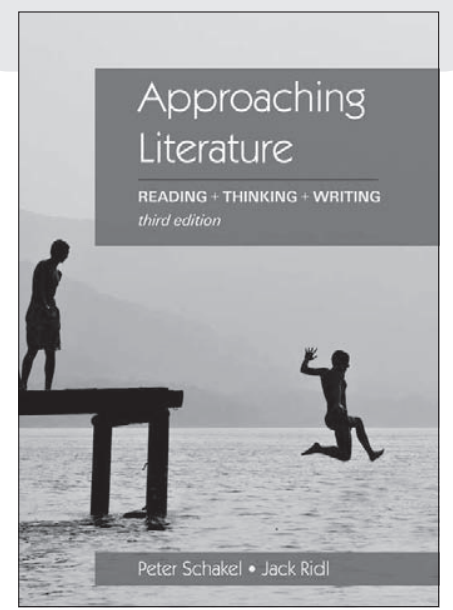

bedfordstmartins.com/ approachinglit/catalog

A great selection of literature at a great price

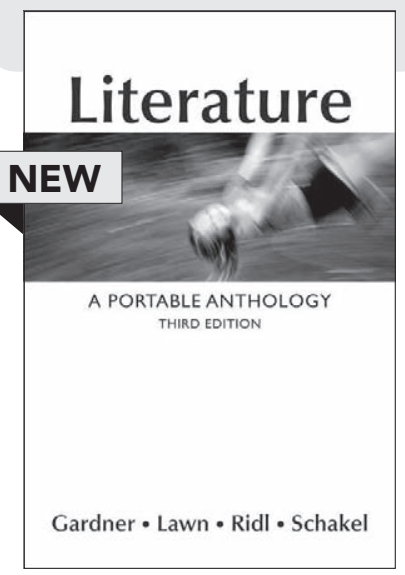

bedfordstmartins.com/ portablelit/catalog 


\section{New Humanities}
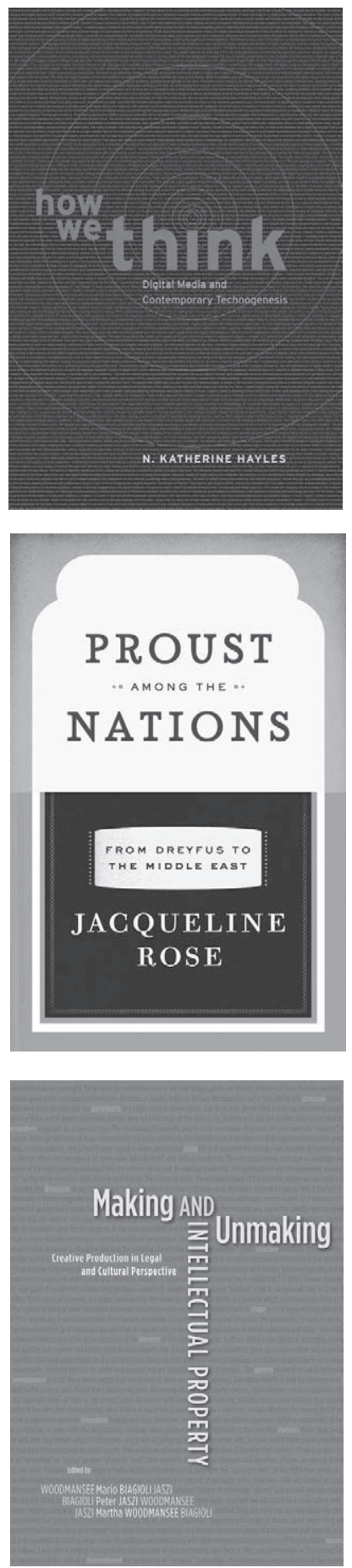

\section{How We Think}

Digital Media and Contemporary Technogenesis

\section{N. Katherine Hayles}

"Compelling, brilliant, remarkable for its breadth and its insightful mapping of the digital humanities. A must read for all humanities scholars wanting to move beyond the hype and hysteria surrounding digital media."-Wendy Hui Kyong Chun, Brown University PAPER $\$ 25.00$

\section{Proust among the Nations \\ From Dreyfus to the \\ Middle East \\ Jacqueline Rose}

"Rose's brilliant achievement in her new book is to argue knowledgeably and persuasively for the relevance that reading Proust and Freud has to the violent antagonism opposing Jews and Arabs in the Middle East." -Leo Bersani, University of California, Berkeley CLOTH $\$ 35.00$

\section{Making and Unmaking Intellectual Property}

Creative Production in Legal and Cultural Perspective

\section{Edited by Mario Biagioli, \\ Peter Jaszi, and Martha Woodmansee}

"Here's a simple prayer: Let no new law regarding 'intellectual property' be passed until all legislators have absorbed the treasures contained in this wonderful collection of essays."-Lewis Hyde, Kenyon College

CLOTH $\$ 115.00$

\section{From Chicago}

\section{The Mosaic Constitution}

Political Theology and Imagination from Machiavelli to Milton Graham Hammill

\section{"The Mosaic Constitution is an} extraordinary work of scholarshipremarkable in its depth and range, remarkable in its implications for the field. ... This impressive book will be the point of reference for scholars engaged with the history of political theology in the early modern era."-Christopher Pye, Williams College CLOTH \$45.00

\section{Songbook}

How Lyrics Became Poetry in Medieval Europe

\section{Marisa Galvez}

"Numerous works exist on the songbooks of individual vernacular cultures, but none has the comparative range of Marisa Galvez's Songbook. This book is groundbreaking, erudite, elegant, and sophisticated, and will be of major importance to medieval and Renaissance scholars of lyric poetry." - Sarah Kay,

Princeton University

CLOTH $\$ 35.00$

\section{Now in Paperback}

\section{Unoriginal Genius}

Poetry by Other Means in the New Century

Marjorie Perloff

"As she has done so often, Perloff makes central what might have seemed marginal, and argues a compelling case for poets, practices, and works that test the limits of unoriginality. Unoriginal Genius is a delight."-Roland Greene, Stanford University

PAPER \$17.50

The University of Chicago Press www.press.uchicago.edu 


\section{Adopt the MLA Handbook for Your Fall Classes.}

\section{Check It Out.}

MLA members can request a complimentary copy at www.mla.org. Each copy includes print and online formats.

\section{Assign It.}

Your students can start using the Handbook the day you assign it. They can buy access online at www.mlahandbook.ors (a print copy will be mailed to them) or purchase a print copy online or at their local bookstore (each print copy comes with an online-access code).

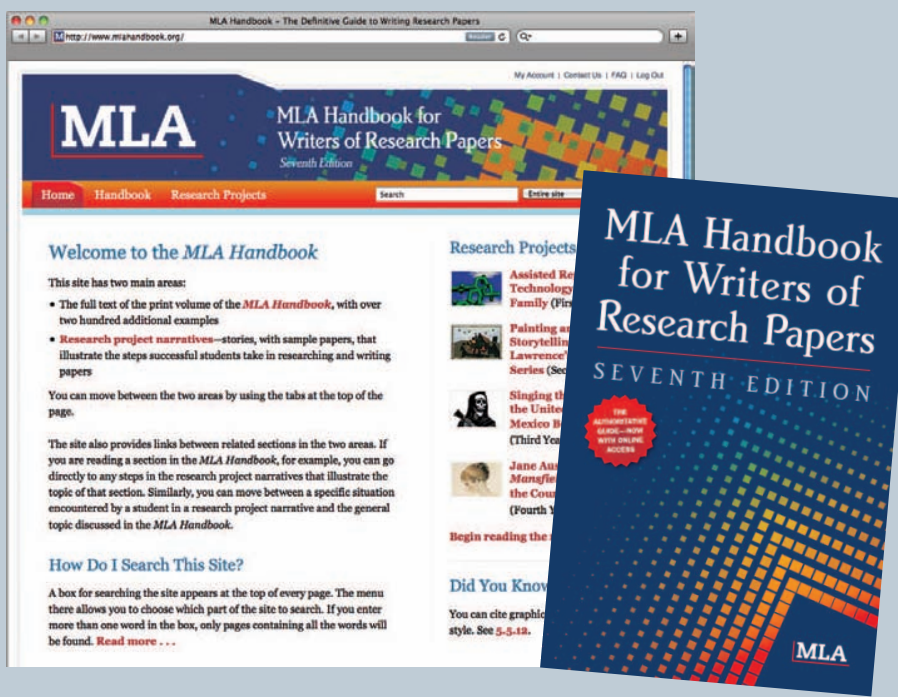

The searchable Web site features

- the full text of the MLA Handbook

- over two hundred additional examples

- research project narratives, with sample papers

xxii \& 292 pp.

Paper 978-1-60329-024-1 \$22.00

A large-print edition is also available.

Recipient of Choice Award for Outstanding Academic Title for 2009

Visit the MLA's channel on YouTube at www.youtube.com/user/ModernLanguageAssoc
Forthcoming in the October issue of PMLA

Special Topic: Work Coordinated by Vicky Unrub

Vicky Unruh. Introduction

David Babcock. "Professional Subjectivity and the Attenuation of Character in J. M. Coetzee's Life \& Times of Michael K"

Rebecca Biron. "It's a Living: Hit Men in the Mexican Narco War"

Judith Hamera. "The Labors of Michael Jackson: Virtuosity, Deindustrialization, and Dancing Work"

Donal Harris. "Finding Work: James Agee in the Office"

Anne-Maria Makhulu. "The

Conditions for after Work:

Financialization and Informalization in Posttransition South Africa"

Anca Parvulescu. "Import/ Export: Housework in an International Frame"

Margaret Ronda. "Work and Wait Unwearying': Dunbar's Georgics"

\section{Papers from the MLA Convention}

Dorian Bell. "Hannah Arendt, the Jews, and the Labor of Superfluity"

Debra A. Castillo. "On the Line: Work and Choice"

John E. Davidson. "Industry in Idealized Form: The Work of Movies in Film's First One Hundred Years"

Bruce Robbins. "On the Rentier"

\section{Theories and Methodologies}

Essays by Gerard Aching, Cristina Della Coletta, Jennifer Rae Greeson, Joseph

Luzzi, Sonali Perera, Laura J. Rosenthal, and Carolyn Steedman

\section{The Changing Profession}

Essays on academics' work by Severino J. Albuquerque, Jane K. Brown, Frieda

Ekotto, Margaret W. Ferguson, Roberta Johnson, Ramón Saldívar, Marcy Schwartz, and Kathleen Woodward

\section{Correspondents at Large}

Essays on the Occupy Movement by Stathis Gourgouris, Celeste Langan, and Walter Benn Michaels 